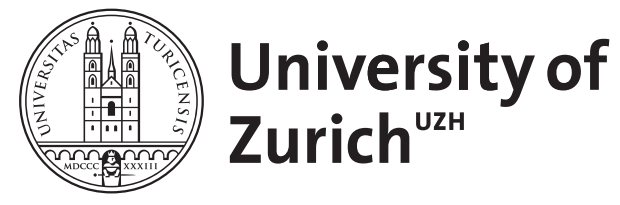
Archive

University of Zurich

University Library

Strickhofstrasse 39

CH-8057 Zurich

www.zora.uzh.ch

Year: 2020

Fetal tuberous sclerosis and the diagnosis of paternal gonadal mosaicism

Tutschek, Boris ; Mayer, Karin ; Rauch, Anita

DOI: https://doi.org/10.1002/uog.21880

Posted at the Zurich Open Repository and Archive, University of Zurich

ZORA URL: https://doi.org/10.5167/uzh-179359

Journal Article

Accepted Version

Originally published at:

Tutschek, Boris; Mayer, Karin; Rauch, Anita (2020). Fetal tuberous sclerosis and the diagnosis of paternal gonadal mosaicism. Ultrasound in Obstetrics Gynecology, 55(5):691-692.

DOI: https://doi.org/10.1002/uog.21880 


\section{Fetal tuberous sclerosis and the diagnosis of paternal gonadal mosaicism}

Boris Tutschek 1, Karin Mayer 2, Anita Rauch 3

1 Prenatal Zurich, Zürich, Switzerland, 2 Center of Human Genetics and Laboratory Diagnostics, Martinsried, Germany, 3 University of Zurich, Schlieren-Zürich, Switzerland

Corresponding author: Boris Tutschek tutschek@me.com

Running Head: Fetal tuberous sclerosis and gonadal mosaicism

Keywords: tuberous sclerosis , rhabdomyoma , next generation sequencing

This article has been accepted for publication and undergone full peer review but has not been through the copyediting, typesetting, pagination and proofreading process which may lead to differences between this version and the Version of Record. Please cite this article as doi: 10.1002/uog.21880 
Tuberous sclerosis complex (TSC) is an autosomal dominant disorder with high clinical variability. TSC is caused by pathogenic variants in the genes TSC1 or TSC2 that regulate cell growth and proliferation. Affected individuals develop benign tumors in many tissues and organs. Neurological manifestations include epilepsy, autism, cognitive and behavioral dysfunction and giant cell tumors. ${ }^{1}$

Fetal cardiac rhabdomyoma can be diagnosed by prenatal ultrasound. ${ }^{2}$ If present, further studies to confirm fetal TSC may be indicated ${ }^{1}$ : Fetal MRI to document or exclude cerebral manifestations, which may escape prenatal ultrasound, and invasive fetal genetic testing.

In a 30-year-old primigravida fetal screening ultrasound had shown an echogenic lesion in the left cardiac ventricle (LV). Detailed fetal assessment at 22 weeks' gestation confirmed a $6 \mathrm{~mm}$ echogenic lesion in the LV (fig. 1A), and additional smaller ones were found in the right ventricular myocardium. Fetal MRI was performed, demonstrating a $17 \mathrm{~mm}$ cerebral lesion close to the foramen of Monroe, visible also on fetal brain ultrasound examination (fig. 1B). Invasive fetal testing showed a likely pathogenic variant c.2423C>T (p.(Leu808Ser) in exon 22 of the TSC2 gene.

Familial history was negative for TSC, but at the time of the fetal examination, the father was noted to have facial skin anomalies, which had previously been diagnosed as angiofibroma (fig. 1C).

DNA extracted from his blood, saliva and an angiofibroma biopsy were tested for TSC1 and TSC2 variants by high-throughput next-generation panel sequencing, but found to be egative. Finally, a semen sample was analyzed using targeted next generation deep sequencing: the TSC2 variant present in the affected fetus was detected in $10 \%$ of the paternal sperm DNA.

Cognitive dysfunction and seizures may develop in infants with TSC, but seemingly healthy adults may not be aware of the potential consequences of innocuous skin lesions, as in this case. Fetal and paternal TSC was suspected at the time of the fetal ultrasound examination. Genetic analysis confirmed TSC in the fetus, but failed to prove paternal TSC in blood, saliva and and skin lesions. Only molecular analysis of sperm DNA confirmed the paternal origin of TSC. The father seems to be spared the dismal consequences of TSC due to his postzygotic low-level mosaicism. In case of fertilization of an egg with a sperm carrying the TSC2 variant, however, the entire conceptus is affected, with anticipated worse sequelae. 


\section{References}

1. Dragoumi P, O'Callaghan F, Zafeiriou DI. Diagnosis of tuberous sclerosis complex in the fetus. Eur J Paediatr Neurol 2018.

2. DeVore GR, Hakim S, Kleinman CS, Hobbins JC. The in utero diagnosis of an interventricular septal cardiac rhabdomyoma by means of real-time-directed, M-mode echocardiography. Am J Obstet Gynecol 1982; 143: 967-969. 


\section{Figure legend}

Fig. 1 Fetal and paternal signs of tuberous sclerosis. 1A Sonographic view of the fetal cardiac four-chamber view at 22 weeks' gestation, showing a $6 \mathrm{~mm}$ echogenic lesion in the left ventricle. 1B. Nasolabial fold of the father of fetus in $1 \mathrm{~A}$, showing facial angiofibroma. 1C. Contrast enhanced volume ultrasound image of the fetal brain at 22 weeks, showing the $17 \mathrm{~mm}$ cerebral lesion next to the median border of the frontal horn of the lateral ventricle (white circle), seen also on fetal MRI. 
